\title{
СРАВНИТЕЛЬНОЕ ИССЛЕДОВАНИЕ ВЫРАЖЕННОСТИ ДЕПРЕССИИ У СТАРШЕКЛАССНИКОВ И СТУДЕНТОВ ВУЗА
}

\section{COMPARATIVE STUDY OF THE SEVERITY OF DEPRESSION IN HIGH SCHOOL STUDENTS AND UNIVERSITY STUDENTS \\ L. Bukhlina \\ M. Tigunova}

Summary: The article presents the results of a study of the severity of depression, its structure, and the manifestation of one of the structural components - a sense of hopelessness - in students of the 11th grade of secondary school and university students of different courses of study; comparative empirical data of depression severity and by samples of young men and girls are given; attention is drawn to the need for psychological work with students with signs of subdepression for the prevention of suicide.

Keywords: depression, subdepression, components of depression, a sense of hopelessness, adolescence.
$\mathrm{H}$ еобходимость решения возрастных психологических и социальных проблем приводит к возникновению у ряда лиц юношеского возраста аффективных нарушений, в частности, депрессивных расстройств. Известно, что депрессия входит в симптоматическое ядро пресуцидного синдрома, поэтому всестороннее исследование этого важнейшего предиктора играет важную роль в остро стоящей перед педагогами школ, ссузов и вузов необходимости профилактики суицида в подростковой и молодежной среде.

Депрессию (от лат. depressio - подавление, угнетение) в современной психологии трактуют как психическое расстройство, проявляющееся в снижении настроения и ангедонии (неспособности получать удовольствие). К дополнительным вариативным симптомам относят: пессимистическую оценку себя и мира, снижение физической активности, нарушение концентрации внимания, расстройства сна и аппетита, суицидальные тенденции. Классическая структура депрессии представляет собой «депрессивную триаду» - тимический, идеаторный и моторный компоненты [1; 2], имеющие некоторую специфику в юношеском возрасте. Показано, что тимический компонент юношеских депрессий проявляется в апатичности, дисфории, тревожности, тоскливости; идеаторные нарушения (трудность усвоения информации, сужение объема восприятия, нарушение различных процессов внимания, снижение объема оперативной памяти, замедление темпа мыслительных
Бухлина Лариса Юрьевна

к.nсх.н., доцент, Пензенский государственный университет

layr111@mail.ru

тигунова Милана Сергеевна ассистент, Пензенский государственный университет» milana.tigunova@mail.ru

Аннотация: В статье предлагаются результаты исследования выраженности депрессии, ее структуры, и проявления одного из структурных компонентов - чувства безнадежности - у обучающихся 11 класса общеобразовательной школы и студентов вуза разных курсов обучения; приводятся сравнительные эмпирические данные выраженности депрессии и по выборкам юношей и девушек; обращается внимание на необходимость психологической работы с обучающимися, имеющими признаки субдепрессии, для профилактики суицида.

Ключевые слова: депрессия, субдепрессия, компоненты депрессии, чувство безнадежности, юношеский возраст.

процессов, снижение речевой продуктивности) в юности часто дополняются ценностно-смысловыми проблемами с доминироваᄀнием идей о неизбежности смерти, бессмысленности существования, плоть до идеи самоуничижения; моторный компонент (снижение активности, заторможенность) довольно редко диагностируется у юношей, однако могут иметь место инверсия режима сна и бодрствования, повышенная сонливость, различные соматовегетативные проявления, нарушения аппетита [3, с. 106-108].

Н.В. Зверева и соавторы выделяют 9 типов юношеских депрессий, различающихся акцентной симптоматикой [3, с. 109], что в очередной раз актуализирует проблему индивидуального подхода в профессиональной деятельности, связанной с лицами юношеского возраста. Т.В. Владимирова отмечает противоречивость результатов исследований юношеских депрессий - одни подчеркивают неблагоприятный прогноз этих состояний, другие оценивают его оптимистично и указывают на значительную частоту полного выздоровления после перенесенных в юности эндогенных депрессий [9, с. 25-26].

В предпринятом нами эмпирическом исследовании сравнивались показатели выраженности депрессии, ее структуры и проявления одного из структурных компонентов - чувства безнадежности - у обучающихся старших классов общеобразовательной школы и студентов вуза. Методическим арсеналом исследования 
послужили «Шкала депрессии» А. Бека и его же «Шкала безнадежности». В модели А. Бека главной психологической причиной депрессии считаются дисфункции мышления, составляющие когнитивную триаду: негативные базисные убеждения относительно собственного «Я», окружающего мира и негативный взгляд на будущее. Негативные базисные убеждения возникают вследствие искажений мышления и проявляются в когнитивных ошибках: в произвольности умозаключений, сверхобобщении, поляризованном («черно-белом») мышлении, персонализации и др. [5, с. 82].

В исследовании участвовали 72 учащихся 11-х классов (42 девушки и 30 юношей) и 90 студентов ФГБОУ ВО «Пензенский государственный университет» 1, 2 и 4 курсов направлений подготовки «Психология» и «Психолого-педагогическое образование» (68 девушки и 22 юноши).

В целом по всей выборке средний показатель $(7,82)$ свидетельствует об отсутствии депрессии. Тот же вывод можно сделать при дифференцировании результатов по половой принадлежности испытуемых: у девушек - 8,07, у юношей - 7,86. Статистических различий в выраженности депрессии между ними не обнаружено $\left(\mathrm{t}_{\text {эмп }}=0,7\right.$ при $\rho \leq 0,05)$. На отсутствии различий могло сказаться меньшее количество юношей в выборке.

Сравнение школьников и студентов выявило более высокий уровень депрессии у студентов (10,31 против 5,33 , различия подтверждены $\left(\mathrm{t}_{\text {эмп }}=3,18\right.$ при $\left.\rho \leq 0,01\right)$. При этом показатель студентов находится на уровне легкой депрессии (субдепрессии), что характеризуется сниженным настроением и спадом активности, эмоциональным дискомфортом, но чаще не мешает заниматься основной деятельностью [6, с. 189]. Принято, однако, включать данный круг лиц в группу риска развития более тяжелых форм депрессии. Средний показатель школьников указывает на отсутствие депрессивной симптоматики.

Показатели выраженности депрессии у девушекшкольниц и девушек-студенток отличаются в средних значениях (выше у студенток), но статистически различия не подтверждены $-\mathrm{t}_{\text {эмп }}=1,82$ при $\rho \leq 0,05$. Другая картина при сравнении юношей - школьников и студентов: показатель первых достоверно меньше $-\mathrm{t}_{\text {эмп }}=2,78$ при $\rho \leq 0,05$. Экстраполировать эти результаты затруднительно из-за малочисленности выборки юношей.

Сравнение общих показателей депрессии у девушек и юношей в школьной выборке в ходе математической обработки не обнаружили различий $\left(_{\text {эмп }}=1,22\right.$ при $\rho \leq 0,05)$. В группе испытуемых-студентов чуть более «депрессивными» оказались юноши (11,73 против 9,85 у девушек), но достоверных различий нет $\left(\mathrm{t}_{\text {эмп }}=0,71\right.$ при $\rho \leq 0,05)$.

Результаты процентного соотношения школьников и студентов с разной степенью выраженности депрессии представлены в таблицах 1,2.

Более 3/4 школьников не имеют признаков депрессии, причем юношей с отсутствием депрессии больше (единичные случаи умеренной и тяжелой депрессии зафиксированы тоже у девушек), что подтверждает многочисленные данные о преобладании случаев депрессии у лиц женского пола.

Депрессия не выявлена у чуть более половины студентов, при этом в подгруппе девушек этот показатель выше $(61,8 \%)$, чем у юношей $(45,4 \%)$. Выраженная депрессия, или депрессия средней тяжести, представлена обычно 4-5 симптомами. Такой уровень депрессии чаще

Таблица 1.

Выраженность депрессии у школьников (в \%)

\begin{tabular}{|c|c|c|c|c|} 
& \multicolumn{4}{|c|}{ Уровни выраженности депрессии } \\
\cline { 2 - 5 } & Отсутствие симптомов & Легкая депрессия & Умеренная депрессия & Тяжелая депрессия \\
\hline Вся группа & 77,8 & 16,6 & 2,8 & 2,8 \\
\hline Девушки & 71,4 & 19,0 & 4,8 & 4,8 \\
\hline Юноши & 86,7 & 13,3 & 0,0 & 0,0 \\
\hline
\end{tabular}

Таблица 2.

Выраженность депрессии у студентов (в \%)

\begin{tabular}{|c|c|c|c|c|c|}
\multirow{2}{*}{} & \multicolumn{5}{|l}{ Уровни выраженности депрессии } \\
\cline { 2 - 6 } & Отсутствие симптомов & Легкая депрессия & Умеренная депрессия & Депрессия ср. тяжести & Тяжелая депрессия \\
\hline Вся группа & 57,8 & 22,2 & 2,2 & 13,4 & 4,4 \\
\hline Девушки & 61,8 & 20,6 & 2,9 & 11,8 & 2,9 \\
\hline Юноши & 45,4 & 27,3 & 0,0 & 18,2 & 9,1 \\
\hline
\end{tabular}


фиксировался у юношей по сравнению с девушками, хотя статистически различия не подтверждены. Выявлено 2 случая депрессии в тяжелой степени - у 1-ой девушки и 1-го юноши (разница в процентах обусловлена меньшим количеством испытуемых-юношей).

Интересна картина выраженности депрессии у студентов в зависимости от курса обучения. По «Шкале депрессии» А. Бека результаты можно трактовать как отсутствие депрессии в целом в выборках 1-го $(8,67)$ и 4-го $(9,31)$ курсов, легкую депрессию - в выборке 2-го курса $(13,19)$. Значимых различий между выборками не обнаружено $\left(\mathrm{H}_{\text {эмп }}=0,16\right.$ при $\left.\rho \leq 0,05\right)$. Больший средний балл выраженности депрессии среди второкурсников, возможно, связан с такой особенностью этой группы как вторая попытка получения высшего образования (31,3\% студентов этого курса ранее начинали учиться на других специальностях, но были разочарованы). Возможно, их завышенные ожидания от обучения по направлению «Психология» также не оправдались. Можно также с осторожностью предположить, что «кризис 3-го курса», хорошо известный в педагогической психологии в предыдущие десятилетия в отношении студентов специалитета, сместился (возможно, из-за уменьшения сроков обучения) в условиях бакалавриата на 2 курс.

«Шкала депрессии» во взрослом варианте предусматривает также различение показателей когнитивно-аффективных и соматических проявлений депрессии, что и было сделано на выборке студентов. Показатели когнитивно-аффективных проявлений депрессии у студентов $(7,28)$ достоверно выше $\left(t_{\text {эмп }}=4,10\right.$ при $\left.\rho \leq 0,05\right)$ по сравнению с показателями соматических проявлений $(3,52)$, т.е. выражены по большей части идеаторный и тимический компоненты депрессии, что согласуется с возрастными особенностями: юность - период эмоциональноидеаторного нервно-психического реагирования на различные стрессовые факторы [3, с. 49]. Достоверных различий между девушками и юношами в выраженности идеаторных и тимических проявлений не выявлено $\left(\mathrm{t}_{\text {эмп }}=0,40\right.$ при $\left.\rho \leq 0,05\right)$, так же, как и в выраженности соматических проявлений ( $\mathrm{t}_{\text {эмп }}=1,00$ при $\left.\rho \leq 0,05\right)$.

Преобладание показателей когнитивно-аффективных компонентов депрессии, по-видимому, связано с тем, что юность является относительно «здоровым» периодом онтогенеза по сравнению с предыдущими и последующими этапами, что на субъективном уровне проявляется у большинства юных людей в низком уровне «самоозабоченности», пренебрежении к возможным соматическим проблемам [7, с. 422]. Нельзя исключать также влияние специфики психологического образования на студентов, актуализирующей рефлексивные процессы. Статистических различий показателей когнитивно-аффективных и соматических проявлений депрессии между группами студентов разных курсов обучения не обнаружено. Наибольшие значения по обеим субшкалам приходятся на студентов 2-го курса, что вполне согласуется с превышением их показателя по общему уровню выраженности депрессии.

«Шкала депрессии» А. Бека позволяет также провести более детальный анализ (21 компонент) выраженности симптоматики депрессии. Анализ показал, что в целом по студенческой выборке наибольшими оказались показатели (в баллах): «Трудности в работе» $(1,00)$, «Пессимизм» $(0,90)$, «Утомляемость» $(0,71)$; наименее выраженными - «Потеря в весе» $(0,13)$, «Озабоченность состоянием здоровья» $(0,16)$, «Плаксивость» $(0,32)$. Таким образом, подтверждается низкий уровень субъективного отражения соматической симптоматики депрессии. Сравнение групп по полу также подтверждает этот тезис: в группе девушек-студенток к наименее выраженным симптомам, кроме названных в отношении всей выборки, прибавился «Потеря аппетита» $(0,29)$.

В мужской части выборки наибольшие баллы набрали, кроме названных «Трудности в работе» $(1,30)$ и «Пессимизм» $(0,90)$, также «Ощущение невезучести», «Неудовлетворенность собой», «Чувство социальной отчужденности», «Утомляемость» (по 0,80 баллов). Эти по большей части когнитивные компоненты депрессии у юношей из студенческой выборки фиксировались чаще, чем у девушек. Можно предположить их взаимодетерминацию: трудности в работе провоцируют мысли о собственной невезучести, неудовлетворенность собой, пессимистическое настроение и, как следствие, чувство отчужденности от социума. Так же, как у девушек, в мужской выборке очень низкие показатели симптоматики депрессии, связанной с внутренним состоянием организма. Статистический анализ результатов не обнаружил достоверных различий по подавляющему большинству параметров. На уровне тенденции обнаружены различия по параметру «Неудовлетворенность собой» $\left(t_{\text {эмп }}=2,10\right.$ при $t_{\text {кр }}=2,05(\rho \leq 0,05)$ и 2,76 $\left.(\rho \leq 0,01)\right)-$ среднегрупповое значение выше у юношей.

Достоверность различий при сравнении группы студентов, у которых была выявлена какая-то степень выраженности депрессии, и группы без признаков депрессии была получена по параметрам «Утомляемость» $\left(\mathrm{t}_{\text {эмп }}=4,81\right)$, «Неудовлетворенность собой» $\left(\mathrm{t}_{\text {эмп }}=4,73\right)$, «Трудности в работе» $\left(\mathrm{t}_{\text {эмп }}=4,43\right)$, «Печаль» $\left(\mathrm{t}_{\text {эмп }}=4,32\right)$, «Нерешительность» $\left(\mathrm{t}_{\text {эмп }}=4,1\right)$, «Ощущение невезучести» $\left(\mathrm{t}_{\text {эмп }}=3,78\right)$, «Самоотрицание» $\left(\mathrm{t}_{\text {эмп }}=3,41\right)$, «Дисморфофобия» $\left(\mathrm{t}_{\text {эмп }}=3,11\right)$. Можно заключить, что именно эти характеристики депрессивного состояния являются «симптоматическим ядром» в переживании депрессии (чаще - субдепрессии) у студентов, принявших участие в диагностических процедурах.

В целом по результатам, полученным по методике 
«Шкала депрессии» А. Бека, можно сделать выводы о большей выраженности депрессии в студенческой выборке, по сравнению со школьниками (77,8\% испытуемых школьной выборки - лица без депрессии), при этом чаще у студентов выявлялась депрессия в легкой степени; в выборке студентов преобладающими являются когнитивно-аффективные проявления депрессии, причем юношам неудовлетворенность собой характерна больше, чем для девушкам; обнаружен больший средний балл выраженности депрессии среди 2-курсников, по сравнению со студентами 1-го и 4-го курсов.

Далее представлены данные по второй методике «Шкала безнадежности» А. Бека, который трактует безнадежность как систему когнитивных схем, общим признаком для которых является негативная окраска ожиданий относительно ближайшего и отдаленного будущего [10].

В таблице 3 представлены результаты по выраженности чувства безнадежности в двух сравниваемых эмпирических выборках.

Показатель по выборке в целом $(3,81)$ свидетельствует об отсутствии чувства безнадежности, однако видно, что среднее значение в группе юношей выше. Это значение позволяет говорить о чувстве безнадежности «в легкой степени», что проявляется, прежде всего, в туманных представлениях о собственном будущем. Различий по полу, однако, не обнаружено ( $\mathrm{t}_{\text {эмп }}=1,61$ при $\left.\rho \leq 0,05\right)$. Нет достоверных различий также между школьниками и студентами $\left(\mathrm{t}_{\text {эмп }}=0,82\right.$ при $\left.\rho \leq 0,05\right)$.

Отдельно в выборке старшеклассников средний показатель также свидетельствует о наличии «легкой безнадежности», что в первую очередь можно связать с актуальным жизненным контекстом - необходимость профессионального самоопределения и процедура ЕГЭ. Хотя достоверных различий в значениях чувства безнадежности между полами в школьной выборке не выявлено $\left(\mathrm{t}_{\text {эмп }}=0,73\right.$ при $\left.\rho \leq 0,05\right)$, у юношей он выше.

Подсчет Т-критерия не подтвердил различий и по другим параметрам сравнения: девушек-студенток и юношей-студентов; девушек-студенток и девушекшкольниц; юношей - студентов и школьников.

Проводился также анализ результатов по такому вектору сравнения, как выраженность когнитивно-аффективных проявлений депрессии (результаты представлены выше) и выраженность чувства безнадежности в студенческой выборке. Подтверждено, что среди тех, у кого в той или иной степени выявлено чувство безнадежности, достоверно выше $\left(\mathrm{t}_{\text {эмп }}=2,71\right)$ показатель когнитивно-аффективных проявлений депрессии, при этом ярче это проявилось у юношей.

В таблице 8 содержатся показатели выраженности чувства безнадежности студентов разных курсов обучения.

Значимых различий между студентами трех курсов нет $\left(\mathrm{H}_{\text {эмп }}=0,29\right.$ при $\left.\rho \leq 0,05\right)$, хотя, если средний показатель 1-го курса $(2,83)$ трактуется, в соответствии с методикой А. Бека, как «отсутствие чувства безнадежности», в группах студентов 2-го $(4,56)$ и 4-го $(3,29)$ курсов средние показатели попадают уже в зону «легкой безнадежности». Очевидный скачок выраженности чувства безнадежности у студентов 2 курса (у них, как было показано выше, и наибольшее среднее значение общего показателя выраженности депрессии) гипотетически объясняется выше описанной отличительной характеристикой этой группы студентов. Понятно, что нельзя переносить эти результаты на характеристику всей генеральной совокупности. Что касается студентов 4 курса, то их «легкая безнадежность» может объясняться ситуацией неопределенности в связи с будущим трудоустройством и изменением жизненного регламента после окончания вуза.

Таким образом, по второй методике А. Бека можно сделать вывод, что как для школьников, так и для студентов в целом не характерно чувство безнадежности. Несколько чаще юноши из двух названных выборок демонстрируют легкую степень его выраженности, так же, как когнитивно-аффективные проявления депрессии, по сравнению с девушками. Объяснение этому обстоятельству, возможно, лежит в области гендерных стереотипов, в рамках которых в российском обществе по-прежнему ожидается больший уровень социальных достижений, карьерных успехов от лиц мужского пола. У юношей 11-го класса могут обостряться опасения не соответствовать этим ожиданиям на этапе ЕГЭ и при выборе профессии, который не гарантирует возможность

Таблица 3.

Выраженность чувства безнадежности (средние значения)

\begin{tabular}{|c|c|c|c|}
\multirow{2}{*}{} & \multicolumn{3}{|c|}{ Показатель безнадежности } \\
\cline { 2 - 4 } & Вся выборка & Школьники & Стденты \\
\hline Вся выборка & 3,81 & 4,06 & 3,62 \\
\hline Девушки & 3,38 & 3,71 & 3,18 \\
\hline Юноши & 4,73 & 4,53 & 5,00 \\
\hline
\end{tabular}


тех самых социальных достижений. Соответственно, на этом основании актуализируются когнитивно-аффективные проявления депрессии и чувство безнадежности, в частности. У юношей-студентов эти проявления могут усугубляться сомнениями в профессиональном выборе и неблагоприятным прогнозом, связанным с трудоустройством.

Выводы по результатам проведенного локального исследования:

- у примерно 1/5 части выборки старшеклассников и 2/5 выборки студентов выявляется депрессивное состояние разной степени выраженности (чаще субдепрессия);

- более выражена депрессия у девушек-школьниц, по сравнению с юношами, и, наоборот, - у юношей-студентов по сравнению с девушками;

- более выражены в студенческой выборке когнитивно-аффективные проявления депрессии (пессимизм, трудности в работе и утомляемость), по сравнению с соматическими;

- юношам-студентам, вне зависимости от наличия или отсутствия у них депрессии, неудовлетворенность собой характерна больше, чем девушкам;

- обнаружен больший средний балл выраженности депрессии среди 2-курсников, по сравнению со студентами 1-го и 4-го курсов;
- в целом для выборки не характерно чувство безнадежности, но среднее значение в группе юношей выше как в школьной, так и в студенческой выборках;

- показатель чувства безнадежности у школьников на уровне средних значений несколько превышает таковой у студентов;

- средние показатели чувства безнадежности студентов 2-го и 4-го курсов выше, чем в группе 1-курсников, и попадают в зону «легкой безнадежности».

Результаты исследования могут представлять интерес для педагогов и психологов, работающих с юношеством. Ими должно быть осознанно, что отсутствие психологической работы с людьми, у которых имеются признаки субдепрессии, влечет за собой дальнейшие деструктивные изменения психики и может привести к серьезным негативным последствиям. В науке доказана связь между выраженностью чувства безнадежности и возникновением депрессии. Поэтому лица с «легкой безнадежностью» также относятся к группе суицидального риска. Депрессия - это единственное состояние, которое влечет за собой огромное количество непредвиденных смертей, поэтому самый эффективный способ предупреждения самоубийств - это раннее выявление и своевременное лечение депрессий $[4,8]$.

\section{ЛИТЕРАТУРА}

1. Бек А., Раш А., Эмери Г. Когнитивная терапия депрессии. - СПб.: Питер, 2013. - 232 с.

2. Бунькова К.М. Депрессии и неврозы / Под ред. М. А. Кинкулькиной. - М.: ГЭОТАР-Медиа, 2011. - 176 с

3. Зверева Н.В., Казьмина 0.Ю., Каримулина Е.Г. Патопсихология детского и юношеского возраста: Учебное пособие для вузов. - 2-е изд., испр. и доп. М.: Юрайт, 2020. - 222 с.

4. Макферсон Л., Моро Д., Вейссман М., Клерман Д. Подросток и депрессия. Межличностная психотерапия / Пер. с англ. - М.: ЭКСМ0, 2003. - 315 с.

5. Падун М.А. Когнитивный стиль и депрессия // Экспериментальная психология. - 2009. - Том 2. - № 4. - C. 81-90. - URL: https://www.elibrary.ru/item. asp?id=13078606 (дата обращения: 26.08.2021).

6. Перре М., Бауманн У. Клиническая психология. - 3-е изд. - СПб.: Питер, 2012. - 960 с.

7. Рощупкина Д.В. Депрессия, тревога и стресс - бич студентов 21 века // Наука в современном мире: вопросы теории и практики: материалы Международной (заочной) научно-практической конференции (София, 15 июня 2018 г.). - Нефтекамск: Научно-издательский центр «Мир науки», 2018. C. 419-425.

8. Семакина Н.В., Злоказова М.В. Скрининг диагностика доклинических форм депрессий у старших школьников // Клинико-биологические, психологические и социальные аспекты психических расстройств у детей и подростков: сборник материалов Всероссийской научно-практической конференции с международным участием (Москва, 16 февраля 2018 г.). - М.: ФГБНУ НЦПЗ. 2018. - С. 173-175.

9. Цуцульковская М.Я., Копейко Г.И., Олейчик И.В., Владимирова Т.В. Роль психобиологических характеристик юношеского возраста в формировании клинической картины депрессий и особенностях терапии // Психиатрия. - 2003. - № 5(5). - C. 21-28. - URL: https://www.elibrary.ru/item.asp?id=18758271 (дата обращения: 26.08.2021).

10. Шкала безнадежности Бека. - URL: https://psylab.info/Шкала_безнадёжности_Бека (дата обращения: 05.04.2021). 